Invited Review

\title{
$\beta$-blockers: Their new life from hypertension to cancer and migraine
}

\author{
Carlo Fumagalli $^{\mathrm{a}, 1}$, Niccolò Maurizi ${ }^{\mathrm{a}, \mathrm{b}, *, 1}$, Niccolò Marchionni ${ }^{\mathrm{a}}$, Diego Fornasari ${ }^{\mathrm{c}}$ \\ ${ }^{a}$ Cardiothoracovascular Department, Azienda Ospedaliero-Universitaria Careggi, University of Florence, Italy \\ ${ }^{\mathrm{b}}$ Hopital du Valais, Department of Internal Medicine, Sion, Switzerland \\ ${ }^{\mathrm{c}}$ Department of Medical Biotechnology and Translational Medicine, Università degli Studi di Milano, Italy
}

A R T I C L E I N F O

\section{Keywords:}

Beta-Blockers

Hypertension

Migraine

Pleiotropy

\begin{abstract}
A B S T R A C T
The pharmacological class of $\beta$-blockers includes a plea of molecules with largely different pharmacokinetic and pharmacodynamic characteristics with a protective effect that may span far beyond the cardiovascular system. Although all these compounds share the pharmacological blockade of the adrenergic receptors, each of them is characterized by specific pharmacological properties, including selectivity of action depending on the adrenergic receptors subtypes, intrinsic sympathomimetic activity (ISA), lipid solubility, pharmacokinetic profile, and also other ancillary properties that impact their clinical effect. Their use in the treatment of hypertension has been extensively debated and at the moment a class indication is not present. However, in specific niche of patients, such as in those young individuals in which hypertension is mainly driven by a sympathetic hyperactivation, strong evidence pose $\beta$-Blockers as a highly reasonable first-line treatment. Lipophilic $\beta$-blockers, specifically propranolol and metoprolol, can cross the Blood Brain Barrier and have a Class A indication for the prophylactic treatment of migraine attacks. Moreover, since $\beta$-adrenergic receptors affect the proliferative process of both cancer and immune cells, their blockade has been associated with metastasis reduction in several epithelial and solid organ tumors posing $\beta$-Blockers as a new attractive, inexpensive and relatively safe therapeutic strategy in patients with several types of cancer. However, further dedicated prospective, randomized, placebo-controlled studies are needed to determine the real efficacy of these compounds.
\end{abstract}

\section{Introduction}

The pharmacological class of $\beta$-blockers include a plea of molecules with largely different pharmacokinetic and pharmacodynamic characteristics, whose clinical indications stemmed from large randomized clinical trials. Despite they have been in clinical use since more than three decades, new indications are still emerging.

In the present review, we will re-assess their clinical usefulness in cardiovascular medicine, focusing on hypertension in which their role is widely debated, and discuss the most recent evidence of their potential extra cardiovascular effects.

\section{Pharmacology of $\beta$-blockers}

$\beta$-adrenergic receptor-blocking agents ( $\beta$-blockers) are among the most widely used classes of drugs in clinical practice. They are competitive antagonists of adrenergic receptors, that can be distinguished for their selectivity profiles versus $\beta-1$ and $\beta-2$ receptors, the presence of intrinsic sympathomimetic activity, differences in lipid solubility that affects penetration into the central nervous system (CNS), inverse agonist properties, capacity to induce vasodilation and, finally, for their specific pharmacokinetics parameters. Three generations of $\beta$-blockers have been developed and entered into the clinical practice over time. The first generation includes only non-subtype-selective drugs, such as propranolol, which have similar affinity for $\beta-1$ and $\beta-2$ receptors. Second generation includes $\beta-1$ selective drugs, such as atenolol, bisoprolol and metoprolol. Third generation contains both selective and non-selective $\beta-1$ subtype drugs that possess additional properties, such as the antagonism on the $\alpha-1$ receptor or the capability of inducing nitric oxide (NO) production, which are properties to be taken into account to optimize their use in the clinical practice.

\section{1. $\beta-1$ versus $\beta-2$ selectivity}

$\beta-1$ receptors are mainly expressed in the heart, where they induce positive chronotropic, dromotropic, bathmotropic and inotropic effects [1], in the juxtaglomerular cells, where they control renin release, and in the CNS, along with $\beta-2$ receptors, where they can mediate

\footnotetext{
* Corresponding author at: Cardiomyopathy Unit, Careggi University Hospital, Viale Pieraccini 17, 50132, Florence, Italy.

E-mail address: niccolo.maurizi@gmail.com (N. Maurizi).

${ }^{1}$ The two authors contributed equally to the manuscript.
} 
Table 1

Main pharmacological properties of commonly used $\beta$-blockers.

\begin{tabular}{|c|c|c|c|c|c|}
\hline DRUG & ISA & LIPID SOLUBILITY & VASODILATION & BIOAVAILABILITY \% & PLASMA T $1 / 2 \mathrm{~h}$ \\
\hline \multicolumn{6}{|c|}{ FIRST GENERATION: non-selective $\beta$-blockers } \\
\hline Nadolol & 0 & Low & 0 & 30 & $20-24$ \\
\hline Penbutolol & + & High & 0 & 90 & 5 \\
\hline Pindolol & +++ & Low & 0 & $90-100$ & $3-4$ \\
\hline Propranolol & 0 & High & 0 & 30 & $3-5$ \\
\hline Timolol & 0 & Low & 0 & 75 & 4 \\
\hline \multicolumn{6}{|c|}{ SECOND GENERATION. Selective $\beta 1$-blockers } \\
\hline Acebutolol & + & Low & 0 & $30-50$ & $3-4$ \\
\hline Atenolol & 0 & Low & 0 & $40-50$ & $6-7$ \\
\hline Bisoprolol & 0 & Low & 0 & 80 & $9-12$ \\
\hline Esmolol & 0 & Low & 0 & - & 0,15 \\
\hline Metoprolol & 0 & Moderate & 0 & $40-50$ & \\
\hline \multicolumn{6}{|c|}{ THIRD GENERATION WITH ADDITIONAL PROPERTIES: non selective $\beta$-blockers } \\
\hline Carteolol & ++ & Low & YES & 90 & 6 \\
\hline Carvedilol & 0 & Moderate & YES & $25-35$ & $7-10$ \\
\hline Labetalol & + & Low & YES & $25-35$ & $3-4$ \\
\hline \multicolumn{6}{|c|}{ THIRD GENERATION WITH ADDITIONAL PROPERTIES: selective $\beta 1$ - blockers } \\
\hline Betaxolol & 0 & Moderate & YES & 80 & 15 \\
\hline Celiprolol & + & Low & YES & $30-70$ & 5 \\
\hline Nebivolol & 0 & Low & YES & - & $11-30$ \\
\hline
\end{tabular}

Abbreviations: ISAIntrinsic Sympathetic Activity; T12/2 hplasma half time.

cardiovascular responses.

$\beta$-2 receptors are mainly expressed in different types of smooth muscle cells located in vessels, especially those in skeletal muscle cells, and visceral hollow organs, such as bronchi or uterus, where they mediate smooth muscle relaxation.

The research of selective $\beta-1$ blockers stemmed from the need of avoiding adverse effects on the respiratory tracts and on vascular tone, and although the selectivity is not absolute, $\beta-1$ selective blockers, such as atenolol, bisoprolol and metoprolol, are better tolerated in patients with asthma and peripheral artery disease. However, as said, selectivity is not absolute, but relative and therefore dose-dependent (Table 1).

$\beta-2$ receptors are also expressed, at a lower level (4:1 $\beta-1 / \beta-2$ receptors), in the normal heart, where they are supposed to participate in sympathetic responses, since they are normally coupled to the Gs, with the production of cAMP. In chronic heart failure (CHF), $\beta-1$ stimulation is known to cause apoptosis of cardiac cells, whereas $\beta-2$ stimulation seems to have an anti-apoptotic and proliferative effect, due to a shift of coupling from Gs to Gi.

\subsection{Intrinsic sympathomimetic activity}

Some of the $\beta$-blockers, first of all pindolol, but also acebutolol, carteolol and celiprolol, are capable of stimulating $\beta-1$ receptors in the absence of catecholamine. These are partial agonists with intrinsic sympathomimetic activity that become functional antagonists in the presence of high concentrations of noradrenaline and adrenaline.

This residual agonistic activity may prevent severe bradycardia and negative inotropy in a resting heart. Nevertheless, it is still unclear whether this property is disadvantageous in specific clinical conditions, such as in the secondary prevention of myocardial infarction or in migraine.

\subsection{Inverse agonistic properties}

Receptors can exist in different conformational states. In the simplest view, most of them are in the inactive state and become activated upon agonist binding. However, many receptors possess basal spontaneous activity and can be activated, triggering transduction cascade, even in the absence of their agonist (Table 1 ).

$\beta-1$ receptors display basal spontaneous activity. This means that at rest, heart, juxtaglomerular cells, rostral ventro-lateral medullar (RVLM) neurons (see below) can be partially stimulated in the absence of catecholamines. Neutral competitive antagonists are drugs that prevent the binding of the endogenous agonist, but do not affect receptor spontaneous activity, whereas inverse agonist are drugs capable of inhibiting basal activity [2]. Inverse agonistic properties of $\beta$ blockers might be relevant in clinical practice. It is well known that excessive activation of cardiac $\beta-1$ receptors in response to catecholamines can cause deleterious effects such as cardiac hypertrophy, myocytes apoptosis, fibroblast hyperplasia, and arrhythmias. However, also constitutive activity of $\beta-1$ receptors can cause persistent deleterious signaling to cardiomyocyte in a decompensating heart, thus suggesting that, compared to neutral antagonist, inverse agonist may exert greater protective effects. $\beta$-blockers with inverse agonist properties are metoprolol, carvedilol, propranolol and bisoprolol, whereas pindolol is considered a neutral antagonist. Their inverse agonist activity has been studied in different experimental models: cell culture, tissues, isolated heart, producing slightly different results in terms of efficacy [2]. In human atrial and ventricular myocardium the established rank order is: metoprolol $>$ bisoprolol $=$ nebivolol $=$ carvedilol $>$ bucindol [3] .

\subsection{Vasodilation}

Some $\beta$-blockers are capable of inducing vasodilation, an ancillary property that can be useful in the treatment of both CHF and hypertension. In particular, nebivolol can stimulate NO production from endothelial cells, apparently through an involvement of $\beta-3$ receptors. Carvedilol has an antagonist activity on $\alpha-1$ receptor which is responsible for vasodilation (Table 1). However, recent data would suggest that vasodilation by nebivolol and carvedilol might be the consequence of biased agonism.

\subsection{Biased agonism}

Activated and phosphorylated G-Protein Coupled Receptors (GPCR), such as adrenergic receptors, can recruit a class of multifunctional proteins, $\beta$-arrestins, which are known to play a central role in receptor desensitization. In the last few years a new paradigm has emerged suggesting that $\beta$-arrestins can also mediate downstream signaling on their own by scaffolding various components of different signaling cascades. The recruitment and the signaling of $\beta$-arrestins is completely independent from other receptor functions, such as the ability of modulating the production of classic second messengers, and can occur as unique receptor response. Synthetic ligands capable of selectively 

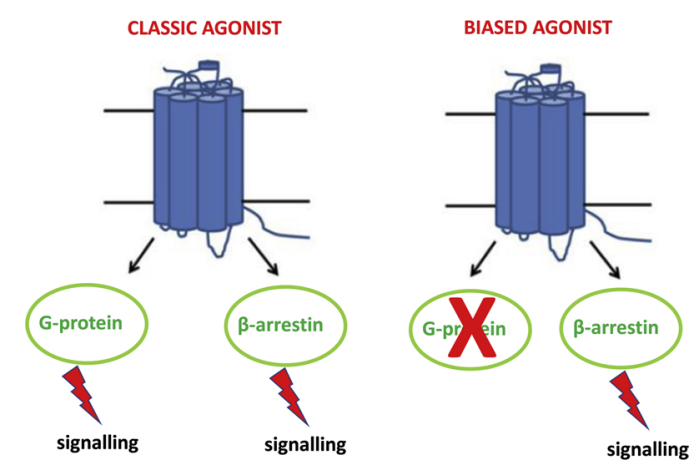

Fig. 1. Signal transduction triggered by classic or biased agonists.

inducing $\beta$-arrestin recruitment and signaling have been identified and described for several GPCRs and are referred to as biased agonists. It has been recently demonstrated that nebivolol and carvedilol, by selectively activating the pathway of $\beta$-arrestin and ERK may stimulate the expression and the activity of eNOS [4,5]. Other $\beta$-blockers might have biased agonist activity and novel pharmacological properties may depend on it (Fig. 1).

\subsection{Pharmacokinetic properties}

$\beta$-blockers show gross differences in term of absorption, metabolism, bioavailability, protein binding and half-life [6]. These different properties influence drug dose, dosing intervals, and appropriateness in patients with renal or hepatic disease, but a detailed discussion of these differences is out of the purposes of this review.

\subsection{Lipid solubility}

Lipid solubility has been considered a detrimental property of $\beta$ blockers. Indeed, $\beta-1$ receptors are expressed in several areas of the CNS, but their accessibility is restricted by the brain-blood barrier (BBB), which is more permissive to lipophilic drugs. Many CNS adverse drug reaction of the most lipophilic $\beta$-blocker, propranolol, which include hallucination, vivid dreams, depression, can be explained by excessive penetration into the CNS.

However, $\beta-1$ receptors are also expressed on the RVLM neurons, which are part of the cardio-regulatory and vasomotor centers of medulla oblongata. The activation of $\beta-1$ receptors stimulate these neurons that, in turn, increase the sympathetic outflow. Therefore, a moderate lipid solubility may be functional to the passage of the drug through BBB and blockade of $\beta-1$ receptors in the CNS [7].

This additional pharmacological property might be useful in arterial hypertension characterized by a sympathetic hyperactivity (see below) or in cardiac tachyarrhythmia. Among $\beta-1$ selective agents, metoprolol and carvedilol are those with moderate lipid solubility (Table 1).

\section{3. $\beta$-blockers and hypertension}

Current American guidelines (Joint National Committee VIII) [8] place $\beta$-blockers as a third therapeutic choice for the treatment of hypertension and similarly, the NICE guidelines state that $\beta$-blockers are not a preferred initial treatment [9]. The only exceptions in which such class of drugs may be considered are for patients intolerant to ACE-Is and angiotensin II receptor blockers (ARBs), for women of childbearing potential, and for subjects with evidence of increased sympathetic drive $[8,9]$. On the contrary, ESC/ESH guidelines do not exclude $\beta$-blockers as one of the options for fist-line antihypertensive treatment [10] and suggest their use in specific conditions associated with hypertension, such as previous myocardial infarction, angina pectoris, CHF and atrial fibrillation. Moreover, several meta-analyses (including patients in a 40-85 years age range) have concluded that $\beta$-blockers are

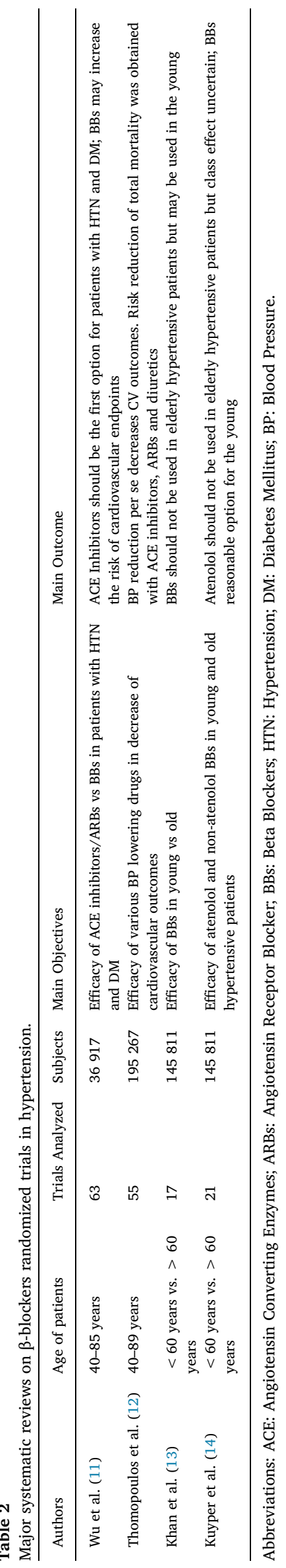


inappropriate first-line agents in the treatment of hypertension $[11,12]$, highlighting they are less effective in reducing cardiovascular events and possibly associated with an increased risk of stroke in the elderly (Table 2). However, since the pathophysiology of primary/essential hypertension differs in elderly and younger subjects, the latter being closely linked to obesity and increased sympathetic nerve activity, the efficacy of $\beta$-blockers in the younger/middle-aged group in reducing the risk of death, and cardiovascular end-points might be greater with respect to other first-line recommended treatments. Therefore, two recent meta-analyses evaluated the efficacy of $\beta$-blockers in the reduction of cardiovascular end-points according to patients' age [13,14]. Khan et al. analyzed 17 studies, including eight randomized placebo-controlled studies and nine trials involving active hypertensive agents [13] (Table 2). In the younger/middle aged hypertensive subjects (mean age $<60$ years), $\beta$-blockers were significantly superior to placebo in reducing the risk of death/stroke/myocardial infarction, while in elderly patients there was with only a positive trend. Kuyper et al. [14] involved 21 studies, comprising the same 17 studies included by Khan et al. [14] plus an extra four studies evaluating patients $<60$ years (3 studies compared propranolol with diuretic, and the fourth - AASK study [15], compared metoprolol with amlodipine and ramipril in Black American hypertensives with renal disease) (Table 2). The conclusion was that in the young/middle-aged ( $<60$ years old) subjects both atenolol and non-atenolol $\beta$-blockers were similarly effective in reducing cardiovascular end-points, while in the elderly, atenolol (no other $\beta$-blocker had been studied) was associated with an increased risk of stroke [14]. The second meta-analysis did not include the most recent follow-up results of the AASK study [16] in younger/middle-age subjects, which showed that metoprolol, amlodipine, and ramipril were similarly effective in reducing cardiovascular outcomes after a 4-year follow-up. These differences can be explained by the fact that diastolic (with or without systolic) hypertension, in contrast to isolated systolic hypertension, occurs primarily in younger subjects, and is linked to overweight/obesity and increased sympathetic nerve activity [17]. In such subgroup of patients, a decrease in heart rate tends to be compensated by a parallel increase in stroke volume, which will elevate systolic but decrease diastolic BP [17]. In younger/middle-aged hypertensives, high plasma norepinephrine levels are linked (independent of blood pressure) to an increased risk of future cardiovascular events and death [18]. High resting heart rates (a surrogate of high sympathetic nerve activity) likewise predict premature all-cause death, coronary heart disease and cardiovascular events in younger hypertensives [18]. In younger/middle-aged hypertensives, antihypertensive agents that increase sympathetic nerve activity (diuretics, dihydropyridine calcium channel blockers, and ARBs) do not decrease (and may increase) the risk of myocardial infarction, and are therefore inappropriate first-line agents in this subset [19]. By contrast, $\beta$-blockers have been shown (vs. placebo or diuretics) to reduce the risk of myocardial infarction by $35-50 \%$, and of stroke by $50-55 \%$ (vs. placebo), in non-smoking hypertensives younger than 60 years of age [20]. Atenolol was at least as effective as the ACE-inhibitor captopril in reducing all cardiovascular endpoints (including stroke, which was reduced by $50 \%$ ), vs. less strict control of blood pressure, in obese hypertensives with type-2 diabetes [21]. After 20 years of follow-up, atenolol was significantly (23\%) superior to the ACE-inhibitor in reducing the risk of all-cause death (on this regard, one may hypothesize that pleiotropic, anti-cancer properties of $\beta$-blockers discussed below, contribute to this protective effect) [22].

Lastly, since all guidelines recommend that life style interventions, such as physical exercise, should be the first-line treatment of hypertension [23-25], $\beta$-blockers play an additional pivotal role, since they are able to control the BP response to physical exercise better than other antihypertensives [26,27]. Such aspect should be taken into consideration when planning treatment for young and middle-aged physically active hypertensive patients.

Thus, we are convinced that international guideline should re- appraise $\beta$-blockers as highly reasonable first-line treatment of hypertension in younger/middle-aged subjects (certainly, in non-smoker, younger men), particularly in those who are obese and with evident sympathetic activation.

\section{Protective effects beyond the CV system: New therapeutic opportunities in cancer and migraine}

\section{1. $\beta$-blockers and cancer: pre-clinical evidence}

Evidence from pre-clinical studies suggests that $\beta$-blockers may exert a protective role in cancer patients by altering the tumor microenvironment and acting against disease progression and metastases. Indeed, $\beta$-adrenergic receptors can be detected on both cancer and immune cells, where they can affect both the proliferative processes and multiple signaling pathways involved in cancer invasion, cancerassociated inflammation, angiogenesis and lymphangiogenesis. In particular, invitro experiments have shown that norepinephrine is a potent inducer of migratory activity in cell lines of colon, prostate, ovarian and breast cancer and, conversely, blockade of $\beta$-adrenergic receptors may favorably modulate immune response and cytokine regulation [28-31]. Importantly, in vivo studies that explored $\beta$-adrenergic receptors pathways suggest a key role of $\beta-2$ receptors in modulating tumor pathophysiology.

Increasing clinical evidence suggests that nonselective compounds, such as propranolol, may have comparable or even greater protective effects than non-selective agents. In general, adrenergic receptors are overexpressed in many epithelial cancers, including colorectal, lung, thyroid, gynecological and urothelial neoplastic lesions. In addition, matching early evidence collected in invitro migration studies, data from the literature suggest that non-selective $\beta$-blockers may positively affect young patients diagnosed with a wide range of epithelial cancers (i.e. colorectal, ovarian, prostate, squamous cell carcinomas, etc.) [32].

\subsection{1. $\beta$-blockers and cancer: clinical evidence}

Despite encouraging pre-clinical data, knowledge of an association of $\beta$-blocker use and cancer prognosis is still limited and somewhat inconsistent, likely reflecting the paucity of available literature and a heterogeneous sensitivity of different cancer subtypes to $\beta$-blocking modulation. Even though specifically designed randomized clinical trials would be needed, observational and case-control studies have shown that exposure to $\beta$-blockers is associated with a reduced prevalence of disease recurrence and a lower cumulative rate of cancerrelated mortality in malignant melanoma [33] and breast cancer. However, other studies failed to show a positive association of $\beta$ blockers with improved overall survival: thus, at present, the efficacy and benefits of anti-proliferative therapies with $\beta$-blockers has been quantified and weighed against three major endpoints, namely cancer recurrence, disease-free survival, and cancer-specific survival. Interestingly, beside differences in cancer types, other factors such as study design (e.g. retrospective vs. prospective) [34] and immortal time bias (ITB, i.e. when a period exists during which the outcome of interest for one of the cohorts cannot possibly occur because of the study design) [35] have been advocated for justifying the large differences in cancerrelated outcomes. In addition, as highlighted in many large systematic reviews and meta-analyses, while it is still unclear which adrenergic receptors are involved in cancer biology, the majority of investigations so far have been conducted with $\beta 1$-selective drugs, such as metoprolol or bisoprolol, while non-selective compounds, like propranolol, were only used in a limited number of studies [34,36-39].

\subsubsection{Cancers that may benefit from $\beta$-blocker therapy}

Several investigations and pooled meta-analyses have shown that, while $\beta$-blockers may not have direct effects on cancer occurrence, they may be significantly associated with long-term cancer-specific survival 8 and improve disease-free survival in ovarian cancers, breast cancer, 
pancreatic cancer and melanoma [34]. In particular, a trend towards an improved disease-free survival with non-selective $\beta$-blockers was noted for melanoma, where the use of propranolol at the time of diagnosis was inversely associated with disease recurrence (with an $80 \%$ risk reduction) $[33,40]$, and for ovarian cancer, in which $\beta$-blocker use correlated with a 6-month longer median survival [41]. Early and perioperative use of non-selective $\beta$-blocker propranolol, alone or in combination with anti-inflammatory drugs, was shown to have synergistic beneficial effects on top of optimal medical and surgical treatment in patients treated for breast cancer, preserving anticancer immunological profiles and reducing epithelial-to-mesenchimal transition and prometastatic transcription factors [34,40,42-44]. Other studies support the use of $\beta$-blockers for pancreatic adenocarcinoma, particularly in those patients who manifested a localized disease $[36,45]$. Interestingly, in this case, no clear difference was observed by $\beta$-blocker receptor selectivity.

Finally, non-selective $\beta$-blockers proved to be a clear possibility in a range of other vascular cancers, including angiosarcomas, in which these drugs significantly prolonged progression-free survival [46-48], and retinal haemangioblastomas in von Hippel-Lindau disease, where propranolol titrated to $120 \mathrm{mg}$ daily stabilized tumors and prevented new lesion development [49].

However, other studies of lung, endometrial, prostate, and headand-neck cancers did not obtain any clinically meaningful evidence for an association of $\beta$-blockers use and survival, after excluding studies with a possible immortal time bias $[34,38,50]$.

However, even in the absence of randomized, double-blind, placebo-controlled clinical trials, all these data collectively support the idea of $\beta$-blockers repurposing within specific fields in oncology. Taken all together, in fact, studies of $\beta$-blockers in cancer are in favor of these agents as a new attractive and inexpensive therapeutic strategy in patients with several types of cancer. Given these persuasive options, further dedicated prospective, randomized, placebo-controlled studies are needed to determine the real efficacy of these compounds.

\section{2. $\beta$-blockers and migraine}

\subsubsection{Headache, migraine: dimensions of the problem}

Migraine and head pain are the fifth leading cause of emergency department visits and top twenty reasons for outpatient visits in the United States [51]. Its prevalence is estimated to $16 \%$ in the general population and is more common in women (with a ratio of 3:1). More than one-in-three persons who have episodic migraines would benefit from prophylactic therapy: however, only $3 \%-13 \%$ manage to receive it and obtain a satisfactory symptom control [52]. This condition negatively affects health-related quality of life and begets depressive symptoms irrespective of age, gender and level of education [53]. The pharmacologic treatment of migraine may be acute (abortive) or prophylactic, and patients with frequent severe headaches may require both. Prophylactic therapy should be used to reduce the frequency, duration, or severity of attacks: success of preventive therapy is defined as a $50 \%$ reduction in attack frequency or headache days, a significant decrease in attack duration, or an improved response to acute medication [54].

Being a chronic condition, once the need for prophylactic treatment is established, therapy should be tailored considering comorbid conditions in order to avoid exacerbate or worsen coexistent illnesses.

\subsection{2. $\beta$-blockers and migraine pathophysiology}

$\beta$-blockers are the most widely used class of drugs in prophylactic migraine treatment and are about $50 \%$ effective in producing a greater than $50 \%$ reduction in attack frequency [55]. However, the pathophysiology of migraine and the mechanisms of action of $\beta$-blockers in migraine prevention are not yet completely understood. Migraine is predominantly a neurogenic rather than a vascular disorder and $\beta$ blockers like metoprolol and propranolol appear to be efficacious 
because they cross the BBB, exploiting their lipid solubility and modify neuronal excitability via $[56,57]$ (Table 3 ). $\beta$-1 receptor antagonism seems to modulate cortical information processing expressed as changes in visual evoked potentials (VEP) mediated through adrenaline and noradrenaline, contingent negative variation (CNV), and auditory evoked potentials (AEP), which are typically abnormal in patients with migraine [58]. Indeed, in patients treated with $\beta$-blockers, the VEP amplitude tends to normalize $[59,60]$.

It has been shown that both metoprolol and propranolol normalize $\mathrm{CNV}$ and that normalization of high CNV correlated positively with treatment response $[61,62]$. Similarly, $\beta$-blockade with metoprolol and bisoprolol decreased the dependence of evoked cortical potentials on the intensity of auditory stimuli in migraine patients, and such a decrease was associated to clinical improvement [63]. All this evidence suggests that $\beta$-blockers modulate cortical excitability and abnormal cortical information processing in migraine.

In addition to their $\beta$-blocking action, however, propranolol and timolol have high affinity for 5-hydroxytryptamine (serotonin or 5-HT) receptors, namely $5 \mathrm{HT} 2 \mathrm{~B}$ and $5 \mathrm{HT} 2 \mathrm{C}$, which play a pivotal role in the pathophysiology of migraine via 5-HT synthesis. Propranolol alone also inhibits nitric oxide production by blocking inducible nitric oxide synthase (NOS) potentially downregulating the activation of the trigeminovascular complex $[64,65]$. Interestingly, it has been shown that $\beta$ blockers with intrinsic sympathomimetic activity (i.e., acebutolol, oxprenolol, pindolol) are not as effective in migraine prevention. Moreover, propranolol interferes with the pharmacokinetics of rizatriptan, a commonly prescribed triptan used in the treatment of migraine, requiring important dose adjustment. Such effect however, is not observed with metoprolol [66].

As a result, for the American Headache Society/American Academy of Neurology guidelines (AHS/AAN) and for European Federation of Neurological Societies (EFNS) among $\beta$-blockers propranolol, metoprolol, and timolol are considered level A drugs (Medications with established efficacy with more than 2 Class I trials) and nadolol is considered a level B drugs (Medications that are probably effective with one Class I or two Class II Studies) for the prophylaxis of episodic migraine. Similar strong recommendations are present in the Canadian Headache Society (CHS) guidelines. (Table 4) [55,67,68] (Table 3).

\subsubsection{Level A $\beta$-blockers}

4.2.3.1. Propranolol. Propranolol, together with metoprolol, is one of the two $\beta$-blockers that are given the highest rating (level $\mathrm{A}$ ) in practice AHS/AAN, CHS, and EFNS guidelines. It is highly lipophilic and therefore it can cross the blood-brain barrier. Compared to other $\beta$ blockers but similarly to metoprolol, the benefits of propranolol appear to be dose-dependent. At relatively low doses of each drug $(50 \mathrm{mg}$ topiramate vs. $80 \mathrm{mg}$ propranolol daily), topiramate results more effective than propranolol [70]. Conversely, a higher dose of propranolol (160 mg daily) has effects similar to those obtained with $1-2 \mathrm{mg} / \mathrm{kg}$ daily of topiramate in terms of responders rate and reduction in migraine frequency, migraine days, and daily rescue medication usage [71]. Propranolol and metoprolol appear similarly effective in controlling migraines; however, the side effect profile of metoprolol appears more favorable [72]. Compared with timolol, propranolol is equally effective and with a similar CNS side effect profile [73].

4.2.3.2. Metoprolol. Together with propranolol, metoprolol is the other $\beta$-blocker with the highest level of evidence across major migraine guidelines. Pharmacologically, it is a moderate lipophilic $\beta-1$ selective agents, without affinity to 5-HT receptors.

Metoprolol has been shown to be more effective than placebo in migraine prophylaxis [74,75]. As for propranolol, its effects are dosedependent, with $100 \mathrm{mg}$ twice daily being mostly effective [76]. As mentioned above, metoprolol appears to have similarly effective as propranolol, but with fewer side effects; to date, no studies have compared the efficacy of metoprolol with other "level A" migraine prophylactic medications in the AAN/AHS guidelines. Moreover, specific formulations of metoprolol are also without specific allergens, i.e. lactose and gluten, thus allowing chronic therapy also in allergic subset of patients.

4.2.3.3. Timolol. Timolol has good affinity for 5-HT2B and 5HT2c receptors, a property that makes it susceptible to potential interactions with other serotonergic drugs. Timolol at a dose of $10-15 \mathrm{mg}$ twice daily is effective when compared to placebo, and about equally effective as propranolol, in decreasing headache frequency, with similar side effect profile [77].

\subsubsection{Level B $\beta$-blockers}

4.2.4.1. Nadolol. Nadolol is a hydrophilic $\beta$-blocker and does not cross the BBB as easily as the other lipophilic compounds. This may prove convenient as it may cause fewer central nervous system side effects such as insomnia and mood depression. Given its longer half-life, unlike propranolol and metoprolol, it allows a single daily dose, which may translate into better adherence [78]. Nadolol was superior to placebo for migraine prophylaxis [59]. However, when comparing $160 \mathrm{mg}$ nadolol daily with $80 \mathrm{mg}$ propranolol twice a day, propranolol was superior in terms of symptom control.

\section{5. $\beta$-blockers in specific patient subset: Diabetes and Obstructive Airway Diseases}

However, concerns have been raised regarding the use of $\beta$-blockers in the diabetic population due to a possible deteriorating metabolic influence and the risk of prolonged hypoglycemia was hypothesized to be higher with non-selective b-blockade in patients using insulin or sulfonylureas [79]. However, no significant difference could be seen in the risk of hypoglycemia with b-blockers in a cohort of 13,559 elderly patients with DM compared with non-users. Only a non-significant trend favoring cardioselective over non-selective b-blockers was registered [80].

Another subset of patients that warrants a specific attention when a $\beta$-blockers is prescribed is represented by Chronic Obstructive Pulmonary Disease (COPD) patients. Recommendations from the Global Initiative for COPD (GOLD), hypertension, HF, CAD, and AF should be

Table 4

$\beta$-blockers for prevention of episodic migraine.

\begin{tabular}{|c|c|c|c|c|c|}
\hline Drug & AHS/AAN Guidelines & CHS Guidelines & EFNS Guidelines & Dose & $\beta$-blockers specific accessory mechanisms \\
\hline Propranolol & A & Strong, high-quality evidence & A & $120-240 \mathrm{mg}$ a day & $\begin{array}{l}\text { Affinity to } 5 \mathrm{HT}_{2 \mathrm{~B}} \text { and } 5 \mathrm{HT}_{2 \mathrm{C}} \text { receptors } \\
\text { Inhibition of inducible nitric oxide synthase }\end{array}$ \\
\hline Metoprolol & A & Strong, high-quality evidence & A & 25 - $100 \mathrm{mg}$ twice daily & \\
\hline Timolol & A & Not rated & Not rated & $10-15 \mathrm{mg}$ twice daily & Affinity to $5 \mathrm{HT}_{2 \mathrm{~B}}$ and $5 \mathrm{HT}_{2 \mathrm{C}}$ receptors \\
\hline Nadolol & B & Strong, moderate evidence & $\mathrm{B}$ & $80-160 \mathrm{mg}$ a day & \\
\hline
\end{tabular}

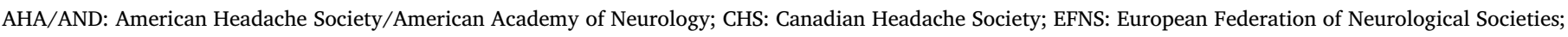

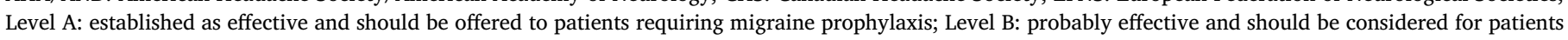
requiring migraine prophylaxis. 
treated according to usual guidelines even in patients with severe COPD. If $\beta$-blockers are indicated, a selective $\beta 1$-blocker (i.e., bisoprolol, metoprolol, or nebivolol) should be chosen and non-selective blockers avoided, especially in higher doses [81]. The ESC guidelines for $\mathrm{HF}$ also encourage the use of selective $\beta 1$-blockers in HF with COPD [82]. The Global Initiative for Asthma (GINA) recommendations do not encourage the use of b-blockers in patients with bronchial asthma; if necessary, treatment should be started under close medical supervision and decisions made on a case-by-case basis (level D evidence). Asthma is not an absolute contraindication for cardioselective b-blockers for acute coronary events, but a careful risk-benefit assessment should be undertaken (level D evidence) [83]. However, a Cochrane review of 29 RCTs of cardioselective $\beta 1$ - blockers found no adverse respiratory effects in the short term in mild-moderate reversible airway disease or COPD [84].

\section{Conclusions}

$\beta$-Blockers are an essential class of cardiovascular medications for reducing morbidity and mortality in various cardiac conditions (Table 4). Their use in the treatment of hypertension has been extensively debated and at the moment a class indication is not present. However, in specific niche of patients, such as in those young individuals in which hypertension is mainly driven by a sympathetic hyperactivation, strong evidence pose $\beta$-Blockers as a highly reasonable first-line treatment. Because of the role in sympathetic outflow of the cardio-regulatory and vasomotor centers of medulla oblongata, which are activated by $\beta-1$ stimulation, moderate lipophilic $\beta$-blockers that cross the $\mathrm{BBB}$ and inhibit the discharge of these neural structures might be more suitable for this class of hypertensive patients. Moreover, after more than 50 years from their discovery, new evidence is emerging, suggesting their protective effect beyond the cardiovascular system. $\beta$ Blockers, specifically propranolol and metoprolol have a Class A indication for the prophylactic treatment of migraine attacks. More interestingly, since $\beta$-adrenergic receptors affect the proliferative process of both cancer and immune cells, their blockade has been associated with metastasis reduction in several epithelial and solid organ tumors (Table 4). All this data collectively support the idea of $\beta$-blockers repurposing within specific fields in oncology. However, whether $\beta$ blockers in cancer represent a new attractive, inexpensive and relatively safe therapeutic strategy in patients with several types of cancer, further dedicated prospective, randomized, placebo-controlled studies are needed to determine the real efficacy of these compounds.

\section{Founding}

Health RCB srl Italy provided founding for the realization of the present manuscript, but had no role in the conceptualization, realization and revision of the work.

None of the authors (C.F., N.M, N.M., D.F.) has relevant conflict of interest concerning the content of the present manuscript.

\section{Declaration of Competing Interest}

None of the authors (C.F., N.M, N.M., D.F.) has relevant conflict of interest concerning the content of the present manuscript.

\section{References}

[1] O.-E. Brodde, H. Bruck, K. Leineweber, Cardiac adrenoceptors: physiological and pathophysiological relevance, J Pharmacol Sci [Internet] 100 (5) (2006) 323-337 [cited 2019 Aug 27] Available from: http://www.ncbi.nlm.nih.gov/pubmed/ 16612046.

[2] C.A. Taira, F. Monczor, C. Höcht, Measurement of inverse agonism in $\beta$-adrenoceptors, Methods in Enzymology, Academic Press Inc., 2010, pp. 37-60.

[3] C. Maack, S. Tyroller, P. Schnabel, B. Cremers, E. Dabew, M. Südkamp, et al., Characterization of $\beta 1$-selectivity, adrenoceptor-Gs-protein interaction and inverse agonism of nebivolol in human myocardium, Br. J. Pharmacol. 132 (8) (2001) 1817-1826.

[4] J.G. Baker, S.J. Hill, R.J. Summers, Evolution of $\beta$-blockers: from anti-anginal drugs to ligand-directed signalling, Trends in Pharmacological Sciences Vol. 32 (2011), pp. $227-234$.

[5] H. Dwivedi, M. Baidya, A.K. Shukla, GPCR signaling: the interplay of gai and $\beta$ arrestin, Curr. Biol. 28 (7) (2018) R324-R327.

[6] W.H. Frishman, M. Alwarshetty, B-adrenergic blockers in systemic hypertension pharmacokinetic considerations related to the current guidelines, Clinical Pharmacokinetics Vol. 41 Adis International Ltd, 2002, pp. 505-516.

[7] N. Oshima, H. Onimaru, K. Yamamoto, H. Takechi, Y. Nishida, T. Oda, et al., Expression and functions of $\beta 1$ - and $\beta 2$-adrenergic receptors on the bulbospinal neurons in the rostral ventrolateral medulla, Hypertens. Res. 1 (November 11) (2014) 976-983 37.

[8] P.A. James, S. Oparil, B.L. Carter, W.C. Cushman, C. Dennison-Himmelfarb, J. Handler, et al., Evidence-based guideline for the management of high blood pressure in adults: report from the panel members appointed to the Eighth Joint National Committee (JNC 8), JAMA 2014 (February 5) (2014) 507-520 311.

[9] B. Williams, N.R. Poulter, M.J. Brown, M. Davis, G.T. McInnes, J.F. Potter, et al., British Hypertension Society guidelines for hypertension management 2004 (BHSIV): summary, BMJ 328 (March 7440) (2004) 634-640.

[10] G. Mancia, R. Fagard, K. Narkiewicz, J. Redon, A. Zanchetti, M. Bohm, et al., ESH/ ESC Guidelines for the management of arterial hypertension: the Task Force for the management of arterial hypertension of the European Society of Hypertension (ESH) and of the European Society of Cardiology (ESC), J. Hypertens. 2013 (July 7) (2013) 1281-1357 31.

[11] H.-Y. Wu, J.-W. Huang, H.-J. Lin, W.-C. Liao, Y.-S. Peng, K.-Y. Hung, et al., Comparative effectiveness of renin-angiotensin system blockers and other antihypertensive drugs in patients with diabetes: systematic review and bayesian network meta-analysis, BMJ. 347 (October) (2013) f6008.

[12] C. Thomopoulos, G. Parati, A. Zanchetti, Effects of blood pressure lowering on outcome incidence in hypertension: 4. Effects of various classes of antihypertensive drugs-overview and meta-analyses, J. Hypertens. 33 (February 2) (2015) 195-211.

[13] N. Khan, F.A. McAlister, Re-examining the efficacy of beta-blockers for the treatment of hypertension: a meta-analysis, CMAJ. 174 (June 12) (2006) 1737-1742.

[14] L.M. Kuyper, N.A. Khan, Atenolol vs nonatenolol beta-blockers for the treatment of hypertension: a meta-analysis, Can. J. Cardiol. 30 (May 5 Suppl) (2014) S47-53.

[15] J.T.J. Wright, G. Bakris, T. Greene, L.Y. Agodoa, L.J. Appel, J. Charleston, et al., Effect of blood pressure lowering and antihypertensive drug class on progression of hypertensive kidney disease: results from the AASK trial, JAMA. 288 (November 19) (2002) 2421-2431.

[16] K. Norris, J. Bourgoigne, J. Gassman, L. Hebert, J. Middleton, R.A. Phillips, et al., Cardiovascular outcomes in the african american study of kidney disease and hypertension (AASK) trial, Am. J. Kidney Dis. 48 (November 5) (2006) 739-751.

[17] J. Fang, S. Madhavan, H. Cohen, M.H. Alderman, Isolated diastolic hypertension. A favorable finding among young and middle-aged hypertensive subjects, Hypertens (Dallas, Tex 1979) 26 (September 3) (1995) 377-382.

[18] P. Palatini, Role of elevated heart rate in the development of cardiovascular disease in hypertension, Hypertens (Dallas, Tex 1979) 58 (November 5) (2011) 745-750.

[19] J.M. Cruickshank, The role of beta-blockers in the treatment of hypertension, Adv. Exp. Med. Biol. 956 (2017) 149-166.

[20] Medical Research Council Working Party, MRC trial of treatment of mild hypertension: principal results, Br. Med. J. Clin. Res. Ed (Clin Res Ed) 291 (July 6488) (1985) 97-104.

[21] UK Prospective Diabetes Study Group, Tight blood pressure control and risk of macrovascular and microvascular complications in type 2 diabetes: UKPDS 38, BMJ. 317 (September 7160) (1998) 703-713.

[22] R.R. Holman, S.K. Paul, M.A. Bethel, H.A.W. Neil, D.R. Matthews, Long-term follow-up after tight control of blood pressure in type 2 diabetes, N. Engl. J. Med. 359 (October 15) (2008) 1565-1576.

[23] J.-L. Balligand, Beta3-adrenoreceptors in cardiovasular diseases: new roles for an "old" receptor, Curr. Drug Deliv. 10 (February 1) (2013) 64-66.

[24] S.F. Vatner, T.H. Hintze, Mechanism of constriction of large coronary arteries by beta-adrenergic receptor blockade, Circ. Res. 53 (September 3) (1983) 389-400.

[25] P. Lund-Johansen, Hemodynamic consequences of long-term beta-blocker therapy: a 5-year follow-up study of atenolol, J. Cardiovasc. Pharmacol. 1 (5) (1979) $487-495$.

[26] R. Mundal, S.E. Kjeldsen, L. Sandvik, G. Erikssen, E. Thaulow, J. Erikssen, Exercise blood pressure predicts cardiovascular mortality in middle-aged men, Hypertens (Dallas, Tex 1979) 24 (July 1) (1994) 56-62.

[27] P. Kokkinos, C. Chrysohoou, D. Panagiotakos, P. Narayan, M. Greenberg, S. Singh, Beta-blockade mitigates exercise blood pressure in hypertensive male patients, J. Am. Coll. Cardiol. 47 (February 4) (2006) 794-798.

[28] E.K. Sloan, S.J. Priceman, B.F. Cox, S. Yu, M.A. Pimentel, V. Tangkanangnukul, et al., The sympathetic nervous system induces a metastatic switch in primary breast cancer, Cancer Res. 70 (September 18) (2010) 7042-7052.

[29] A. Chang, Walker A.K. Le CP, S.J. Creed, C.K. Pon, S. Albold, et al., beta2Adrenoceptors on tumor cells play a critical role in stress-enhanced metastasis in a mouse model of breast cancer, Brain Behav. Immun. 57 (October) (2016) 106-115.

[30] C.K. Pon, J.R. Lane, E.K. Sloan, M.L. Halls, The beta2-adrenoceptor activates a positive cAMP-calcium feedforward loop to drive breast cancer cell invasion, FASEB J Off Publ Fed Am Soc Exp Biol. 30 (March 3) (2016) 1144-1154.

[31] S.W. Cole, A.K. Sood, Molecular pathways: beta-adrenergic signaling in cancer, Clin. Cancer Res. 18 (March 5) (2012) 1201-1206.

[32] S.L. Rains, C.N. Amaya, B.A. Bryan, Beta-adrenergic receptors are expressed across diverse cancers, Oncoscience. 4 (July 7-8) (2017) 95-105. 
[33] V. De Giorgi, M. Grazzini, S. Benemei, N. Marchionni, E. Botteri, E. Pennacchioli, et al., Propranolol for off-label treatment of patients with melanoma: results from a cohort study, JAMA Oncol. 4 (February 2) (2018) e172908.

[34] A. Yap, M.A. Lopez-Olivo, J. Dubowitz, G. Pratt, J. Hiller, V. Gottumukkala, et al., Effect of beta-blockers on cancer recurrence and survival: a meta-analysis of epidemiological and perioperative studies, Br. J. Anaesth. 121 (July 1) (2018) 45-57.

[35] S. Suissa, Immortal time bias in pharmaco-epidemiology, Am. J. Epidemiol. 167 (February 4) (2008) 492-499.

[36] Z. Na, X. Qiao, X. Hao, L. Fan, Y. Xiao, Y. Shao, et al., The effects of beta-blocker use on cancer prognosis: a meta-analysis based on 319,006 patients, Onco. Ther. 11 (2018) 4913-4944.

[37] C.H. Choi, T. Song, T.H. Kim, J.K. Choi, J.-Y. Park, A. Yoon, et al., Meta-analysis of the effects of beta blocker on survival time in cancer patients, J. Cancer Res. Clin. Oncol. 140 (July 7) (2014) 1179-1188.

[38] J. Weberpals, L. Jansen, P.R. Carr, M. Hoffmeister, H. Brenner, Beta blockers and cancer prognosis - the role of immortal time bias: a systematic review and metaanalysis, Cancer Treat. Rev. 47 (June) (2016) 1-11.

[39] S. Zhong, D. Yu, X. Zhang, X. Chen, S. Yang, J. Tang, et al., Beta-Blocker use and mortality in cancer patients: systematic review and meta-analysis of observational studies, Eur. J. Cancer Prev. 25 (September 5) (2016) 440-448.

[40] V. De Giorgi, S. Gandini, M. Grazzini, S. Benemei, N. Marchionni, P. Geppetti, Effect of beta-blockers and other antihypertensive drugs on the risk of melanoma recurrence and death, Mayo Clin. Proc. 88 (November 11) (2013) 1196-1203.

[41] J.L. Watkins, P.H. Thaker, A.M. Nick, L.M. Ramondetta, S. Kumar, D.L. Urbauer, et al., Clinical impact of selective and nonselective beta-blockers on survival in patients with ovarian cancer, Cancer. 121 (October 19) (2015) 3444-3451.

[42] L. Shaashua, M. Shabat-Simon, R. Haldar, P. Matzner, O. Zmora, M. Shabtai, et al., Perioperative COX-2 and beta-adrenergic blockade improves metastatic biomarkers in breast Cancer patients in a Phase-II randomized trial, Clin. Cancer Res. 23 (August 16) (2017) 4651-4661.

[43] L. Zhou, Y. Li, X. Li, G. Chen, H. Liang, Y. Wu, et al., Propranolol attenuates surgical stress-induced elevation of the regulatory t cell response in patients undergoing radical mastectomy, J. Immunol. 196 (April 8) (2016) 3460-3469.

[44] S. Raimondi, E. Botteri, E. Munzone, C. Cipolla, N. Rotmensz, A. DeCensi, et al., Use of beta-blockers, angiotensin-converting enzyme inhibitors and angiotensin receptor blockers and breast cancer survival: Systematic review and meta-analysis, Int. J. Cancer 139 (July 1) (2016) 212-219.

[45] R. Udumyan, S. Montgomery, F. Fang, H. Almroth, U. Valdimarsdottir, A. Ekbom, et al., Beta-blocker drug use and survival among patients with pancreatic adenocarcinoma, Cancer Res. 77 (July 13) (2017) 3700-3707.

[46] W. Chow, C.N. Amaya, S. Rains, M. Chow, E.B. Dickerson, B.A. Bryan, Growth attenuation of cutaneous angiosarcoma with propranolol-mediated beta-blockade, JAMA Dermatol. 151 (November 11) (2015) 1226-1229.

[47] C.N. Amaya, M. Perkins, A. Belmont, C. Herrera, A. Nasrazadani, A. Vargas, et al., Non-selective beta blockers inhibit angiosarcoma cell viability and increase progression free- and overall-survival in patients diagnosed with metastatic angiosarcoma, Oncoscience. 5 (March 3-4) (2018) 109-119.

[48] E. Pasquier, N. Andre, J. Street, A. Chougule, B. Rekhi, J. Ghosh, et al., Effective management of advanced angiosarcoma by the synergistic combination of propranolol and vinblastine-based metronomic chemotherapy: a bench to bedside study, EBioMedicine. 6 (April) (2016) 87-95.

[49] V. Albinana, R.M.J. Escribano, I. Soler, L.R. Padial, L. Recio-Poveda, K. Villar Gomez de Las Heras, et al., Repurposing propranolol as a drug for the treatment of retinal haemangioblastomas in von Hippel-Lindau disease, Orphanet J. Rare Dis. 12 (June 1) (2017) 122.

[50] J. Weberpals, L. Jansen, W.E. Haefeli, M. Hoffmeister, M. Wolkewitz, Herk-Sukel M.P.P. van, et al., Pre- and post-diagnostic beta-blocker use and lung cancer survival: a population-based cohort study, Sci. Rep. 7 (June 1) (2017) 2911.

[51] T.A. Smitherman, R. Burch, H. Sheikh, E. Loder, The prevalence, impact, and treatment of migraine and severe headaches in the United States: a review of statistics from national surveillance studies, Headache. 53 (March 3) (2013) 427-436.

[52] R.B. Lipton, M.E. Bigal, M. Diamond, F. Freitag, M.L. Reed, W.F. Stewart, Migraine prevalence, disease burden, and the need for preventive therapy, Neurology. 68 (January 5) (2007) 343-349.

[53] R.B. Lipton, S.W. Hamelsky, K.B. Kolodner, T.J. Steiner, W.F. Stewart, Migraine, quality of life, and depression: a population-based case-control study, Neurology. 55 (September 5) (2000) 629-635.

[54] S.D. Silberstein, Preventive migraine treatment, Continuum (Minneap Minn). 21 (August 4 Headache) (2015) 973-989.

[55] J.L. Jackson, E. Cogbill, R. Santana-Davila, C. Eldredge, W. Collier, A. Gradall, et al., A comparative effectiveness meta-analysis of drugs for the prophylaxis of migraine headache, PLoS One 10 (7) (2015) e0130733.

[56] S.D. Silberstein, S. Holland, F. Freitag, D.W. Dodick, C. Argoff, E. Ashman, Evidence-based guideline update: pharmacologic treatment for episodic migraine prevention in adults: report of the Quality Standards Subcommittee of the American Academy of Neurology and the American Headache Society, Neurology. 78 (April 17) (2012) 1337-1345.

[57] T. Sprenger, M. Viana, C. Tassorelli, Current prophylactic medications for migraine and their potential mechanisms of action, Neurotherapeutics. 15 (April 2) (2018)
$313-323$

[58] Y. Zhang, N. Sun, X. Jiang, Y. Xi, Comparative efficacy of $\beta$-blockers on mortality and cardiovascular outcomes in patients with hypertension: a systematic review and network meta-analysis, J. Am. Soc. Hypertens. 11 (July 7) (2017) 394-401.

[59] P.J. Goadsby, P.R. Holland, M. Martins-Oliveira, J. Hoffmann, C. Schankin, S. Akerman, Pathophysiology of migraine: a disorder of sensory processing, Physiol Rev [Internet] 97 (April 2) (2017) 553-622. Available from: http://www.ncbi.nlm. nih.gov/pubmed/28179394\%0Ahttp://www.pubmedcentral.nih.gov/ articlerender.fcgi? artid = PMC5539409.

[60] A. Danesh, P.C.H. Gottschalk, Beta-blockers for migraine prevention: a review article, Curr. Treat. Options Neurol. 21 (March 4) (2019) 20.

[61] M. Siniatchkin, F. Andrasik, P. Kropp, U. Niederberger, H. Strenge, N. Averkina, et al., Central mechanisms of controlled-release metoprolol in migraine: a doubleblind, placebo-controlled study, Cephalalgia. 27 (September 9) (2007) 1024-1032.

[62] J. Schoenen, Noordhout M. de, M. Timsit-Berthier, M. Timsit, Contingent negative variation and efficacy of beta-blocking agents in migraine, Cephalalgia. 6 (December 4) (1986) 229-233.

[63] P.S. Sandor, J. Afra, A. Ambrosini, J. Schoenen, Prophylactic treatment of migraine with beta-blockers and riboflavin: differential effects on the intensity dependence of auditory evoked cortical potentials, Headache. 40 (January 1) (2000) 30-35.

[64] A.A. Pradhan, Z. Bertels, S. Akerman, Targeted nitric oxide synthase inhibitors for migraine, Neurotherapeutics. 15 (April 2) (2018) 391-401.

[65] N.M. Ramadan, Prophylactic migraine therapy: mechanisms and evidence, Curr. Pain Headache Rep. 8 (April 2) (2004) 91-95.

[66] M.R. Goldberg, D. Sciberras, M. De Smet, R. Lowry, L. Tomasko, Y. Lee, T.V. Olah, J. Zhao, K.P. Vyas, R. Halpin, P.H. Kari, I. James, Influence of beta-adrenoceptor antagonists on the pharmacokinetics of rizatriptan, a 5-HT1B/1D agonist: differential effects of propranolol, nadolol and metoprolol, Br. J. Clin. Pharmacol. 52 (July 1) (2001) 69-76.

[67] E. Loder, R. Burch, P. Rizzoli, The 2012 AHS/AAN guidelines for prevention of episodic migraine: a summary and comparison with other recent clinical practice guidelines, Headache 52 (June 6) (2012) 930-945.

[68] S. Evers, J. Afra, A. Frese, P.J. Goadsby, M. Linde, A. May, et al., EFNS guideline on the drug treatment of migraine-revised report of an EFNS task force, Eur. J. Neurol. 16 (September 9) (2009) 968-981.

[70] F. Ashtari, V. Shaygannejad, M. Akbari, A double-blind, randomized trial of lowdose topiramate vs propranolol in migraine prophylaxis, Acta Neurol. Scand. 118 (November 5) (2008) 301-305.

[71] H.-C. Diener, P. Tfelt-Hansen, C. Dahlof, M.J.A. Lainez, G. Sandrini, S.-J. Wang, et al., Topiramate in migraine prophylaxis-results from a placebo-controlled trial with propranolol as an active control, J. Neurol. 251 (August 8) (2004) 943-950.

[72] K. Linde, K. Rossnagel, A. Erskine, Propranolol for migraine prophylaxis, Cochrane Database Syst. Rev. 2017 (2) (2017) CD003225.

[73] P. Tfelt-Hansen, B. Standnes, P. Kangasneimi, H. Hakkarainen, J. Olesen, Timolol vs propranolol vs placebo in common migraine prophylaxis: a double-blind multicenter trial, Acta Neurol. Scand. 69 (January 1) (1984) 1-8.

[74] H.D. Langohr, W.D. Gerber, E. Koletzki, K. Mayer, G. Schroth, Clomipramine and metoprolol in migraine prophylaxis-a double-blind crossover study, Headache. 25 (March 2) (1985) 107-113.

[75] C. Hedman, A.R. Andersen, P.G. Andersson, N.E. Gilhus, P. Kangasniemi, J.E. Olsson, et al., Symptoms of classic migraine attacks: modifications brought about by metoprolol, Cephalalgia. 8 (December 4) (1988) 279-284.

[76] T.J. Steiner, R. Joseph, C. Hedman, F.C. Rose, Metoprolol in the prophylaxis of migraine: parallel-groups comparison with placebo and dose-ranging follow-up, Headache. 28 (February 1) (1988) 15-23.

[77] V. Limmroth, M.C. Michel, The prevention of migraine: a critical review with special emphasis on beta-adrenoceptor blockers, Br. J. Clin. Pharmacol. 52 (September 3) (2001) 237-243.

[78] A. Sudilovsky, A.H. Elkind, R.E.S. Ryan, J.R. Saper, M.A. Stern, J.H. Meyer, Comparative efficacy of nadolol and propranolol in the management of migraine, Headache. 27 (September 8) (1987) 421-426.

[79] S. Jacob, K. Rett, E.J. Henriksen, et al., Antihypertensive therapy and insulin sensitivity: do we have to redefine the role of beta blocking agents? Am. J. Hypertens. 11 (10) (1998) 1258-1265.

[80] R.I. Shorr, W.A. Ray, J.R. Daugherty, et al., Antihypertensives and the risk of serious hypoglycemia in older persons using insulin or sulfonylureas, JAMA. 278 (1) (1997) $40-43$.

[81] J. Vestbo, S.S. Hurd, A.G. Agust1', et al., Global strategy for the diagnosis, management, and prevention of chronic obstructive pulmonary disease: GOLD executive summary, Am. J. Respir. Crit. Care Med. 187 (2013) 347-365.

[82] Piotr PONIKOWSKI, et al., ESC Guidelines for the diagnosis and treatment of acute and chronic heart failure: The Task Force for the diagnosis and treatment of acute and chronic heart failure of the European Society of Cardiology (ESC). Developed with the special contribution of the Heart Failure Association (HFA) of the ESC, Eur. J. Heart Fail. 2016 (2016) 891-975 18.8.

[83] Global Initiative for Asthma, Global Strategy for Asthma Management and Prevention, (2016) http://www.ginasthma.org.

[84] Shelley R. SALPETER, et al., Cardioselective beta-blockers for reversible airway disease, Cochrane Database Syst. Rev. 4 (2002). 